\title{
Retention of First-Year Undergraduate Engineering Students: Role of Psy- chosocial Interventions Targeting First-Generation College Students
}

\author{
Ms. Jennifer Maritza Paz, The University of Texas at Austin, Cockrell School of Engineering \\ Jennifer Paz is a graduate student of the Department of Educational Psychology at The University of Texas \\ at Austin. She received her Bachelor's Degree in Psychology from Texas State University in 2011. She is \\ currently working with Dr. Mia Markey in the Biomedical Engineering Department at The University of \\ Texas at Austin in a project aimed at improving retention rates of first-generation engineer students.
}

Ms. Margo Cousins, University of Texas, Austin

Ms. Cousins oversees undergraduate and graduate academic advising at the Department Biomedical Engineering at The University of Texas at Austin. She directs the office in strategic academic and professional development advising, capstone projects program, industry partnerships, first-year interest groups, and other special programs.

\section{Dr. Cindy D. Wilson, University of Texas, Austin}

Cindy Wilson is the Director of Academic Projects at the Cockrell School of Engineering at the University of Texas at Austin. She has worked at UT Austin since 2000.

She holds a PhD in Higher Education Administration from UT Austin and an MA Degree from Teachers College, Columbia University. Her BA is also from Columbia.

\section{Dr. Mia K. Markey, The University of Texas at Austin}

Dr. Mia K. Markey is a Professor of Biomedical Engineering and Engineering Foundation Endowed Faculty Fellow in Engineering at The University of Texas at Austin as well as Adjunct Professor of Imaging Physics at The University of Texas MD Anderson Cancer Center. A 1994 graduate of the Illinois Mathematics and Science Academy, Dr. Markey earned her B.S. in computational biology (1998) from Carnegie Mellon University and her Ph.D. in biomedical engineering (2002), along with a certificate in bioinformatics, from Duke University.

The mission of Dr. Markey's Biomedical Informatics Lab is to develop decision support systems for clinical decision making and scientific discovery. For example, Prof. Markey leads a collaborative, multiinstitutional team that is designing a decision support system to help breast cancer survivors understand their likely appearance changes following breast reconstruction and, therefore, enable them to choose a reconstruction strategy that will lead to maximal psychosocial adjustment.

Dr. Markey has been recognized for excellence in research and teaching with awards from organizations such as the American Medical Informatics Association, the American Society for Engineering Education, the American Cancer Society, and the Society for Women's Health Research. She is a Fellow of the American Association for the Advancement of Science (AAAS) and a Senior Member of both the IEEE and the SPIE. Dr. Markey is the editor of Physics of Mammographic Imaging (Taylor and Francis, 2012). This text gives an overview on the current role and future potential of new alternatives to mammography in the context of clinical need, complementary approaches, and ongoing research. 


\section{Retention of First-Year Undergraduate Engineering Students: Role of Psychosocial Interventions Targeting First-Generation College Students}

Introduction

An increasing number of students are making the decision to enroll in higher education institutions to obtain a four-year degree. The rise in the number of college students has led to a growth in student diversity in college campuses across the nation ${ }^{1}$. One particular group that has contributed to increased enrollment is first-generation college students, defined as a student whose parents did not earn a four-year degree. First-generation college students constitute about $15-20 \%$ of the student population in American universities ${ }^{2}$. However, even though the enrollment of first-generation students is rising, the retention rates are not parallel to enrollment rates. First-generation students are still less likely than continuing-generation students to enroll in post-secondary institutions, and those that do enroll are less likely to complete a four-year degree $^{3-4}$. First-generation students are more likely to come from low-income families and are less prepared academically ${ }^{5}$. Furthermore, first-generation students are less likely to choose a major field in science, mathematics, and other STEM related fields ${ }^{6}$. This is a national concern as the demand for STEM related jobs grows. Engineering is especially affected by this trend as it has historically experienced difficulties with student retention and attracting a diverse cohort, including first-generation students.

Aware of this disparity, colleges are interested in furthering their understanding about what factors influence student retention. From an economical perspective, higher retention is more cost-effective for universities. But retention also has an effect on the reputation of a university and how it compares to other institutions, as retention is used to help inform external rankings that infer the overall quality of education that the university offers ${ }^{7}$. As a result, many student success programs have been created and are a big part of many major colleges since the late 1990s. In order to help meet the needs of students and ameliorate dropout rates, these programs have primarily focused on factors such as financial and academic preparedness ${ }^{8}$. However, psychosocial barriers, such as a student's sense of belongingness in the institution, can be more difficult to address appropriately and effectively. Programs that fail to acknowledge the connection between psychosocial barriers and other barriers, such as finances, may be less effective at helping first-generation college students succeed in college. For example, firstgeneration college students possess limited social capital (resources accrued through social networks) ${ }^{9}$. As a result, they are less likely to utilize or have more difficulty in recognizing university support, due to their limited experience in seeking such services ${ }^{10}$. Therefore, it is essential to pair resources with guidance on how to utilize them and ways to obtain key contacts that will facilitate resource access.

The transition to college is quite impactful for first-generation students as it often includes a cultural adaptation ${ }^{11}$. The values of the colleges tend to mirror the values of an individualistic culture; that is, values that promote self-identity and independence and are commonly associated with the mainstream white-collar middle class of the US ${ }^{12}$. Many first-generation students better identify with a collectivistic perspective, which promotes community and selflessness. For example, first-generation students more often report that factors related to financial security are very important to them, such as giving their own children better opportunities than their own ${ }^{12}$. 
By contrast, first-generation students are less likely than their counterparts to emphasize measures related to having political power as matters of importance ${ }^{13}$. The disparity between the values of an institution and that of an individual can make it difficult to promote integration of the two entities. Thus, failure to adapt to the mainstream collegiate culture may have detrimental outcomes for a first-generation student and influence their ultimate success.

A bachelor's degree is the surest path to higher socioeconomic status and for a first-generation student to earn a comparable salary as their continuing-generation peers ${ }^{14}$. The field of engineering is a growing sector of the economy that offers some of the best paid careers in the United States, which makes it a desirable degree for a lot of students ${ }^{15}$. However, it is highly competitive and has a higher dropout rate. It is estimated that about one half of the students who begin studies in an engineering field will not earn a degree in engineering ${ }^{16}$. The scarcity of qualified engineering professionals has a profound impact in both social and economic terms ${ }^{17}$. This factor is particularly salient for first-generation students, as they are even more likely to abandon their pursuit of an engineering degree ${ }^{18}$. As a way to contribute to the efforts of engineering retention, our study focuses on psychosocial interventions for first-year college students in engineering. The module employs interventions that have been demonstrated to improve academic and psychosocial outcomes for first-generation college students in other disciplines. The activities of the module include the Values Affirmation Intervention as a writing exercise, and the Difference-Education Intervention in the form of a student panel.

The Values Affirmation Intervention (VAI) was first pioneered by Cohen, et al. in 2006 to narrow the academic achievement gap between racial and ethnic minority middle school students (Blacks and Hispanics) and their white peers. This writing activity has been proven to promote self-integrity and self-worth, which can help with better performance on challenging tasks ${ }^{19}$. The VAI contains a broad list of values not directly related to academic performance that have been validated by past research ${ }^{20}$. To complete the activity, students are instructed to circle two or three values from a list that are of personal importance, write a few sentences explaining why the chosen values are important, and indicate the strength of their agreement with a list of value statements on a numerical scale ${ }^{2}$. The VAI has been widely used to mitigate stereotype threat for minorities and women ${ }^{21}$. Harackiewicz et al. conducted a study in 2013 in which the VAI exercise was introduced to first-generation college students enrolled in an introductory biology course. The intervention was found to narrow the achievement gap, as measured by the final grade in the course, between first-generation and continuing-generation students by $50 \%$, and increased retention by $20 \%$, as measured by an increase in enrollment in the second semester of biology $\mathrm{y}^{2}$.

The Difference-Education Intervention (DEI) was designed by Stephens et al. in 2014 to help reduce the achievement gap between first- and continuing-generation first-year college students $^{22}$. Stephens' DEI is composed of a student panel group from diverse socioeconomic backgrounds who answered specific questions regarding the role that their background played in their college experience in positive and negative ways, telling their personal stories to demonstrate how their background mattered and what strategies they used for success. The contrast between first-generation and continuing-generation students' stories provides the firstyear college students with an understanding that their socioeconomic background matters. Specifically, the panelists' stories provide psychological resources to help first-generation 
students make sense of their college experience, increase their comfort, and ability to effectively transition to college and improve their academic performance ${ }^{22}$.

Purpose of the study

The goal of this study was to design, implement, and evaluate a flexible module for use in engineering first-year seminar courses (First-Year Interest Groups, or FIGs) in order to improve retention and success for first-generation college students. The module sought to replicate the VAI and DEI techniques in an engineering setting at a major university.

Method

Overview

Staff facilitators of the engineering FIGs were approached about allowing time in three class periods in the semester, at the discretion of the facilitators. Each date was dedicated to the VAI writing exercise, the DEI student panel, or the post-intervention survey. Figure 1 shows the overall process to deliver the interventions and survey in the 22 FIGs that participated. The first class period (50 minutes) allotted 10 minutes for the study to be introduced and to seek consent according to Institutional Review Board requirements for accessing grades and GPA in the future, followed by 20 minutes for the VAI writing exercise. The VAI has been found to be most effective when given before a challenging academic task. While this was something that our study tried to pursue whenever possible, it was difficult to achieve such precise timing for every FIG section. Rather, our aim was to have every FIG section do the VAI as early as possible in the semester, so as to catch as many students before a significant course exam. The DEI student panel was conducted on a later class day for the whole period (50 minutes). Toward the end of the semester, a 15-minute post-intervention survey was given in the class. The post-intervention survey was used to gather demographic information and assess participants' college transition, through specific psychological constructs and behaviors. 
Figure 1: Flowchart of module process

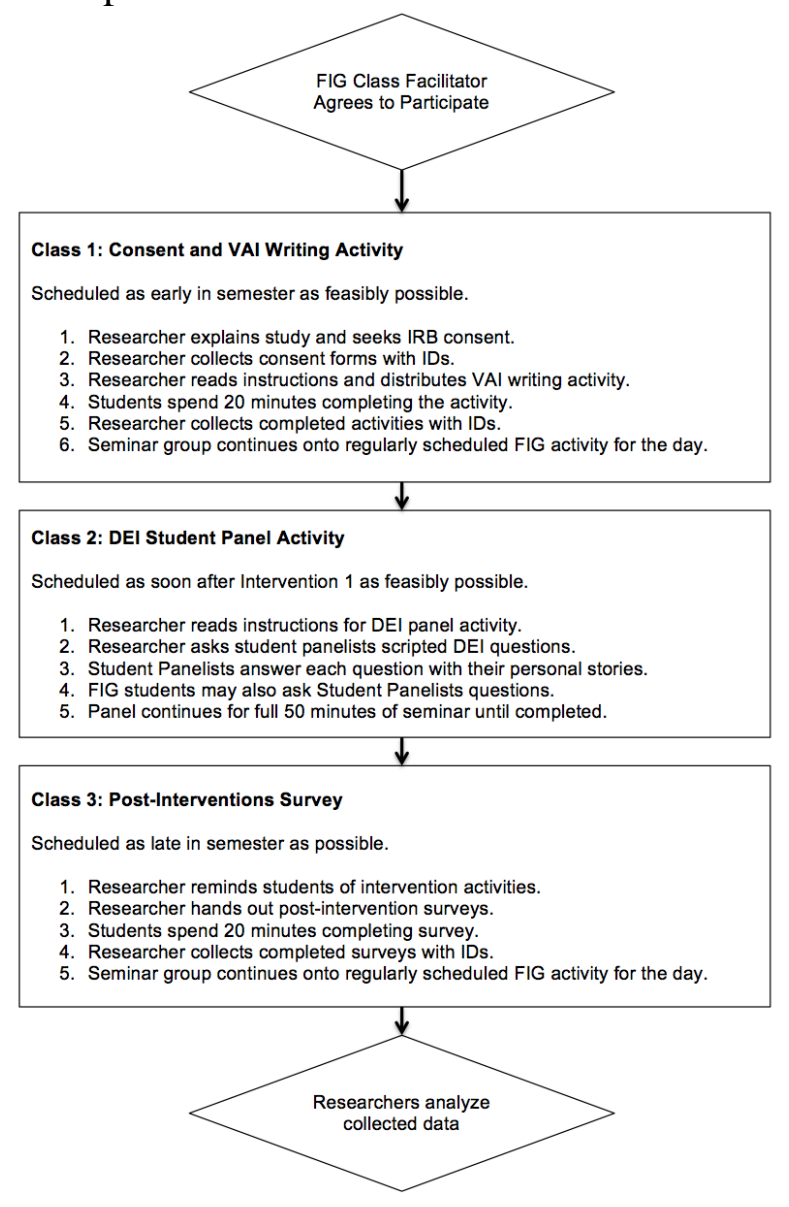

Participants

Each FIG course section includes 10-20 first-year college students, 1 third- or fourth-year student mentor, and 1 staff facilitator. Within the 43 engineering FIG sections, some are major-specific, while others include a range of engineering majors, and others are geared specifically toward women or underrepresented minorities in engineering. Out of the 43 engineering FIGs, 22 sections agreed to add the intervention modules to their seminar. However, 4 sections could not participate in the DEI panel due to scheduling constraints. A total of 311 students enrolled in the 22 sections agreed to participate in the study and gave the researchers consent to look at their end-of-semester grades and GPA. It is important to note that all students in the participating 22 sections, not just the 311 students who gave consent for their grades to be analyzed, were exposed to the interventions since they were adopted as part of the course. Racial and ethnic demographic data were extracted from information gathered by the university for the entire firstyear cohort. The sample of 311 participants consisted of 74 (24\%) Asians; 142 (46\%) Whites; 4 (1\%) Blacks; 65 (21\%) Hispanics/Latinos; 15 (5\%) Multiracial; and 11 (3\%) unknown (these were students that were described as "foreign" or the institution did not have this information available).

Of the 311 participants, 242 (78\%) self-reported generational status and other demographic information through the post-intervention survey. Of the 242 who responded to the question 
regarding their generational status, $33(14 \%)$ identified as first-generation college students, and $209(86 \%)$ identified as continuing-generation. With regard to gender, $90(37 \%)$ identified as female and $152(63 \%)$ identified as male.

\section{Interventions}

The VAI writing activity was the first intervention implemented in all 22 participating sections, scheduled as early in the semester as was feasibly possible. All sections conducted the VAI within the first two months of the semester. The activity was a three-page packet provided in person to each participant present in class. In the event that a student was absent, a follow up email was sent to give the students the opportunity to participate. The students were told that they had 15-20 minutes to complete the exercise. The following prompt was read to ensure everyone received the same information and understood the content of their work:

In class today, you are going to be doing a writing assignment. This will give you additional practice in both critical thinking and writing, which are essential parts of any career in engineering. However, this will be about something that you know well and doesn't require that you studied for it. This writing exercise is confidential and will not be seen by anyone other than the research investigators for this study. There are no right or wrong answers and do not worry about writing technicalities such as spelling or grammar. Instead, focus your writing process on your personal reflections. If you have any questions, please let me know and I will be glad to assist you.

The first page of the activity listed 12 broad values not directly related to academic performance: being good at art; creativity; relationships with family and friends; government or politics; independence; learning and gaining knowledge; athletic ability; belonging to a social group (such as your community, racial group, or school club); music; career; spiritual or religious values; and a sense of humor. The instructions asked students to circle 2-3 values that are of personal importance.

Page 2 of the activity asked students to write a few sentences explaining why each of the chosen values were important to them.

Page 3 started by prompting the student to look back at the values circled on page 1, and asked them to list their top 2 reasons why these values were important to them. Page 3 ends by asking students to indicate the strength of their agreement with specific value statements using a numerical scale. The value statements were: these values have influenced my life; in general, I try to live up to these values; these values are an important part of who I am; I care about these values. The numerical scale was: 1 is strongly disagree; 2 is disagree; 3 is undecided; 4 is agree; 5 is strongly agree.

The VAI writing exercise was completed by a total of 331 students across the 22 participating freshman seminar sections; as previously stated, 311 (94\%) gave consent to use their academic records data for the study. The response style varied significantly per student as some wrote very little content and didn't use the time allotted for the activity, while others provided longer 
responses and used most or all of the time given. Further analyses are planned to find if the amount of writing has any relation to other variables, such as generational status and GPA.

The DEI student panel activity was conducted in a subsequent class period, as soon after the VAI as was feasibly possible. Due to scheduling constraints, the time elapsed between the VAI and the DEI activities was not uniform across the sections. Some sections conducted the two interventions in two weeks consecutively (FIG classes meet once per week). Other sections had 4 to 8 weeks between the interventions. $18(82 \%)$ of the 22 participating sections were able to conduct the second intervention; 4 were unable due to scheduling constraints for the class.

Every attempt was made to recruit an equal number of first-generation and continuing-generation students for each panel, but due to panelists' class schedules the numbers were not equal for each panel; both generation statuses were represented 16 of 18 panels. Some of the FIGs were specifically designed for women or minorities in engineering; therefore, to accommodate the goals of those sections, only women or minority panelists participated in those sections, respectively. Both male and female genders, and a range of engineering disciplines such as chemical engineering, electrical engineering, and biomedical engineering, were represented as much as scheduling would allow. Some panelists participated in as many as six panels, while others were involved in as few as one. Table 1 shows the gender and generational status of the student panelists.

Every panel had a facilitator who lead the session and began by reading the following prompt:

Welcome everyone and welcome to The University of Texas at Austin. We appreciate your participation in the student panel, and hope that today's experience will be valuable for your transition to college. In this session, you will get to hear the stories and experiences of your peers. They were once first-years too, and look forward to sharing their perspectives with you. There will be six questions addressed to the student panel today. Each of the speakers has prepared some thoughts and remarks to share with you. First, the speakers will introduce themselves. They will start by saying their name, year, major, and where they are from. Then, they will answer a series of questions about their experiences at UT.

Each panelist was then asked the following six intervention questions:

1) People come to college for many different reasons. What did coming to college mean to you?

2) Students can have a wide variety of experiences when they transitions to college and come from many different backgrounds. Thinking back, what was the transition to UT like for you?

3) Now we'd like you to share some specific challenges about coming to college. Can you provide an example of an obstacle that you faced when you came to UT and how you resolved it?

4) Did you decisions to attend UT affect your relationships with your friends and family at home? If yes, how?

5) What would you advise other students to do with backgrounds similar to your own? 
6) What experiences that you had prior to UT prepared you to excel in ways that you wouldn't have anticipated at the time?

Table 1 Panel sessions

\begin{tabular}{|c|c|c|c|c|c|}
\hline & $\begin{array}{c}\text { First- } \\
\text { Generation }\end{array}$ & $\begin{array}{c}\text { Continuing- } \\
\text { Generation }\end{array}$ & Male & Female & $\begin{array}{c}\text { Total } \\
\text { Panelists }\end{array}$ \\
\hline Panel 1 & 2 & 2 & 1 & 3 & 4 \\
\hline Panel 2 & 1 & 3 & 2 & 1 & 4 \\
\hline Panel 3 & 3 & 3 & 3 & 3 & 6 \\
\hline Panel 4 & 2 & 2 & 4 & 0 & 4 \\
\hline Panel 5 & 2 & 2 & 2 & 2 & 4 \\
\hline Panel 6 & 1 & 1 & 0 & 2 & 2 \\
\hline Panel 7 & 2 & 1 & 2 & 1 & 3 \\
\hline Panel 8 & 1 & 2 & 2 & 1 & 3 \\
\hline Panel 9 & 2 & 2 & 2 & 2 & 4 \\
\hline Panel 10 & 1 & 3 & 2 & 2 & 4 \\
\hline Panel 11 & 1 & 1 & 2 & 0 & 2 \\
\hline Panel 12 & 1 & 3 & 3 & 1 & 4 \\
\hline Panel 13 & 2 & 3 & 5 & 0 & 5 \\
\hline Panel 14 & 3 & 1 & 3 & 1 & 4 \\
\hline Panel 15 & 0 & 3 & 2 & 0 & 3 \\
\hline Panel 16 & 1 & 3 & 3 & 1 & 4 \\
\hline Panel 17 & 0 & 3 & 0 & 3 & 3 \\
\hline Panel 18 & 1 & 3 & 3 & 1 & 4 \\
\hline Total & 26 & 40 & 18 & & 66 \\
\hline
\end{tabular}

\section{Post-Intervention Survey}

The post-interventions survey was scheduled during a subsequent class period after the DEI panel and as late into the semester as was feasibly possible. The number of weeks between the DEI panel and the survey varied, depending on the individual scheduling constraints of each section. The 4 sections that did not have the DEI panel also participated in the survey.

$242(78 \%)$ of the 311 participants completed the survey. Of the students who completed the survey, $33(14 \%)$ were identified as first-generation, and $209(86 \%)$ as continuing-generation.

Students were given 15 minutes to fill out the survey in class, and could complete the survey online or on paper. The questions in the survey consisted of demographic information as well as dependent measures to assess the effectiveness of the interventions. The survey had a total of 65 questions that assessed several dependent measures that were used in prior studies as well as questions that were composed for the unique aims of our study. The questions derived from the 
studies we based our module on assessed academic identification, perspective taking, social fit, perceived behaviors (tendency to seek college resources), motives for attending college (independent or interdependent). We also thought it would be of interest to know if the participants have siblings currently in college or have obtained a bachelor's degree. We thought that this group of students, while still first-generation students, might differ from other firstgeneration students who do not have siblings in college or with a bachelor's degree. In addition, we asked questions about the amount of time the student spends talking/texting to family and friends from back home as well as an estimate of about how many times they visit home in a month. We also asked students if they dropped any courses during their first semester. To assess the students' level of connection to their own FIG, we incorporated a survey that measures classroom community. This paper describes analysis of one of the sets of questions on this extensive survey, namely the 12 items that assess the extent to which students endorse independent or interdependent motivations for attending college ${ }^{24}$. The measure of independent motivation was the mean of the 6 items that corresponded to independent motivations and the measure of interdependent motivation was likewise taken as the mean of the corresponding 6 items. Missing values were imputed as the mean of the non-missing values for the given item across all students in the sample. Only 8 such values had to be imputed in this manner since most students completed all of the items; most (5) of the missing values were on the final item that queried the extent to which students were motivated to attend college to help their families out after college.

\section{End-of-semester outcomes}

The GPA of each participant for the first semester and his/her retention in engineering were obtained through the institutional records per an approved IRB protocol. Tutoring attendance data from the engineering tutoring sites were collected to determine how frequently participants utilized college resources.

Results

There were many more continuing-generation students $(\mathrm{N}=209)$ than first-generation students $(\mathrm{N}=33)$ in our sample. The proportions of men among the continuing-generation $(129 / 209=62 \%)$ and first-generation students $(23 / 33=70 \%)$ in our sample were similar $(\mathrm{p}=0.49$, Yates-corrected chi-square test for binomial proportions). The gender imbalance observed in our sample is less extreme than is typical for engineering at our institution; for example, the entire first-year cohort from which this sample was drawn was 890/1239=72\% male. Hence, the proportion of male students in our sample as a whole $(152 / 242=63 \%)$ was lower than that for the students who belonged to FIGs that did not participate in our study $(702 / 933=75 \%$; $p<0.01$, Yates-corrected chi-square test for binomial proportions). This makes sense because some of the FIG sections that opted to participate in this study have a substantially larger proportion of women, particularly the groups designed for women in engineering.

We also considered the racial and ethnic diversity of our study sample relative to comparison groups in our School. There was a much smaller fraction of the first-generation students in our sample who reported their race/ethnicity as white-only $(6 / 33=18 \%)$ than among the continuinggeneration students $(109 / 209=52 \%)(\mathrm{p}<0.01$, Yates-corrected chi-square test for binomial 
proportions). The most commonly identified race/ethnicity for first-generation students in our sample was Hispanic $(16 / 33=49 \%)$. In contrast, the most commonly identified race/ethnicity for continuing-generation students in our sample was white-only $(109 / 209=52 \%)$, followed by Asian $(49 / 209=23 \%)$.

There was no difference in the median values of the measure of independent motivations to attend college between the continuing-generation (6.17) and first-generation students in our sample (6.17) $(p=0.90$, Wilcoxon rank sum test). In contrast, the median values of the measure of interdependent motivations to attend college were 5.17 for the continuing-generation students and 6.00 for the first-generation students, where higher scores indicate that the students more strongly endorsed the associated items. Thus, the first-generation students reported more interdependent motives for attending college ( $p<0.01$, Wilcoxon rank sum test).

The median first-semester GPA for the students in our sample was 3.58 (all GPAs in this manuscript are on a 4.0 scale). For reference, the median first-semester GPA for the cohort of first-year engineering students from which our sample was drawn was 3.53. A quantile-quantile plot of the GPAs of students in our sample against a standard normal distribution suggests that the GPA data are not normally distributed. Thus, all statistical comparisons of GPAs were performed using non-parametric tests. The median first-semester GPA for the students in our sample (3.58) was not different from that of students who belonged to FIGs that did not participate in our study $(3.52 ; \mathrm{p}=0.14$, Wilcoxon rank-sum test). The median first-semester GPA for the male (3.58) and female (3.54) students in our sample were not different $(\mathrm{p}=0.89$, Wilcoxon rank-sum test).

The median first-semester GPA for the first-generation students in our sample (3.31) was lower than that of the continuing-generation students in our sample $(3.59 ; \mathrm{p}<0.01$, Wilcoxon rank-sum test). The difference in first-semester GPA between the first-generation and continuinggeneration students persisted even when other factors were considered. As described above, the racial and ethnic diversity of the first-generation students in our study was quite different from that of the continuing-generation students; hence, we also made comparisons within the racial/ethnic group for the most populated category. The median first-semester GPA of the firstgeneration students who identified as Hispanic (3.15) was lower than that of the continuinggeneration students who identified as Hispanic (3.46; $p=0.04$, Wilcoxon rank-sum test).

We investigated whether or not students used the tutoring resources available through the School. For these analyses, a student was considered to have used the tutoring resources if she/he utilized the tutoring service even once in the fall 2014 semester. A larger proportion of students in our sample used the tutoring resources $(64 / 242=26 \%)$ than did students who belonged to FIGs that did not participate in our study $(170 / 933=18 \% ; \mathrm{p}<0.01$, Yates-corrected chi-square test for binomial proportions). We are also encouraged that the proportion of first-generation students in our sample who used tutoring resources $(11 / 33=33 \%)$ was similar to that of the continuinggeneration students in our sample who used the tutoring resources $(53 / 209=25 \% ; p=0.45$, Yates-corrected chi-square test for binomial proportions). The proportion of female students in our sample who used the tutoring services $(32 / 90=36 \%)$ was higher than that of the male students $(32 / 152=21 \%)$ in our sample $(\mathrm{p}=0.02$, Yates-corrected chi-square test for binomial proportions). In contrast, for students who belonged to FIGs that did not participate in our study, 
there was no difference in the rate at which female $(41 / 231=18 \%)$ and male students $(129 / 702=18 \%)$ utilized the tutoring resources $(p=0.91$, Yates-corrected chi-square test for binomial proportions). The gender difference in tutoring utilization between our study sample and the other students in FIGs appears to be due to differences in the study behaviors of the women. Male students in our sample used the tutoring resources at a rate $(32 / 152=21 \%)$ similar to that of male students who belonged to FIGs that did not participate in our study $(129 / 702=18 \% ; p=0.51$, Yates-corrected chi-square test for binomial proportions). On the other hand, female students in our sample used the tutoring resources a higher rate $(32 / 90=36 \%)$ than that of female students who belonged to FIGs that did not participate in our study $(41 / 231=18 \%$; $\mathrm{p}<0.01$, Yates-corrected chi-square test for binomial proportions).

Table 2: Sample size according to generational status and gender

\begin{tabular}{|l|l|l|l|}
\hline $\mathrm{N}$ & Continuing-Generation & First-Generation & Total \\
\hline male & 129 & 23 & 152 \\
\hline female & 80 & 10 & 90 \\
\hline Total & 209 & 33 & 242 \\
\hline
\end{tabular}

\begin{tabular}{|l|l|l|l|}
\hline $\begin{array}{l}\text { N-Continuing } \\
\text { Generation }\end{array}$ & White & Asian & Hispanic \\
\hline male & 72 & 29 & 21 \\
\hline female & 37 & 20 & 16 \\
\hline Total & 109 & 49 & 37 \\
\hline
\end{tabular}

\begin{tabular}{|l|l|l|l|l|}
\hline $\begin{array}{l}\text { N-First } \\
\text { Generation }\end{array}$ & White & Black & Asian & Hispanic \\
\hline male & 4 & 2 & 6 & 8 \\
\hline female & 2 & 0 & 0 & 8 \\
\hline Total & 6 & 2 & 6 & 16 \\
\hline
\end{tabular}

Table 3: Tutoring count according to generational status

\begin{tabular}{|l|l|l|l|}
\hline $\begin{array}{l}\text { N-Tutoring } \\
\text { Usage }\end{array}$ & Continuing-Generation & First-Generation & Total \\
\hline male & 26 & 6 & 32 \\
\hline female & 27 & 5 & 32 \\
\hline total & 53 & 11 & 64 \\
\hline
\end{tabular}




\section{Discussion}

This study was designed to incorporate a module that included psychosocial interventions for first-year students in an engineering freshman seminar course. The study looked to replicate interventions that have previously been shown useful in recent studies to reduce the achievement gap between first-generation and continuing-generation students.

GPA data was collected for the current freshmen cohort to evaluate any effects that could be attributed to the interventions employed in the participating FIG sections. Contrary to what has been found in the previous work from which our interventions are based on, there is still a substantial gap in GPA between first-generation and continuing-generation students that participated in our module. In addition, we do not currently have GPA and generation status data for FIGs from prior years. Thus, at this time we do not know how the GPA gap we observed compares to past cohorts of first- and continuing-generation students. We are working with our colleagues to determine if appropriate historical data can be identified for comparison.

Our goal was to offer the interventions to as many FIG sections as possible since the interventions were found to be beneficial in published studies. To achieve this goal, we had to be very flexible with the FIG leaders, which precluded the level of control of the randomized published studies that established these interventions. Some of the FIG sections plan their semester schedule far in advance. When we reached out to the FIG sections, many of them already had scheduling conflicts to accommodate the module. In the future, we will be able to reach out to the FIG sections with more lead-time.

Our GPA analysis was subdivided into racial/ethnic groups for first- and continuing-generation students. Since the Hispanic group was the largest ethnic group for first-generation students in our sample, it was compared to the continuing-generation students who identified as Hispanic. The comparison revealed that the GPA gap between first-generation and continuing-generation students persisted even when GPA comparisons were made within a single ethnic group. Therefore, the GPA gap we observed between first- and continuing-generation students is not explained by race/ethnicity. This finding is consistent with prior literature that shows that being a first-generation student is a disadvantage within any given race/ethnic group ${ }^{25}$.

Future work will include comparing the GPA and retention data to historical controls, i.e., students who participated in the FIG sections in previous years before the module was introduced. Another area that can provide interesting findings is to evaluate how SAT/ACT scores correlate with GPA, after the module has been implemented. The authors are committed to following this cohort of students in the subsequent semesters so that the end-of-year GPA and retention data can be further evaluated.

Tutoring data were also evaluated to track the students' behavior with respect to utilizing campus resources. The studies in the prior literature that motivated this work suggested that the 
interventions we adopted influence such behavior. A previous study has found that firstgeneration students are less likely to utilize or have more difficulty in recognizing university support, due to their limited experience in seeking such services ${ }^{10}$. For our study, a student was considered to have used tutoring services even if only utilized once in the semester. It was found that tutoring usage was proportionally higher for the students in our sample than for the students in the FIG sections that did not participate in our study. First- and continuing-generation students in our study were compared and found that there was no gap in tutoring usage between the two groups. This could be a result to the interventions in our module, particularly the DEI panel, in which panelists often discussed the importance of tutoring at the university level. However, historical data on tutoring utilization for first- and continuing-generation students in our School are needed to help interpret the results of this study. Another interesting observation in this research was the difference in tutoring utilization for women in the intervention sample relative to the women in the comparison group. However, interpretation for this group is complex as our sample had a relatively large representation of the FIG sections from the Women in Engineering Program (WEP). Further investigation is needed to clarify whether the difference can be directly tied to the intervention.

The literature states that first-generation students are more likely to have a hard transition into the university as it requires a cultural adaptation ${ }^{11}$. University values tend to mirror those of an individualistic culture, largely seen in the white-collar middle class. First-generation students tend to better identify with a collectivistic perspective. This can cause first-generation students to feel alienated, due to the mismatch of values. To gather a better perspective of what values our sample of students better identified with, the survey incorporated questions that assessed motivation for attending college, based on independent and interdependent motives. No differences were found in the measure of independent motivation to attend college between continuing- and first-generation students in our sample. However, first generation students reported more interdependent motives for attending college. The findings indicate that firstgeneration students in our sample have adopted independent motives to the same degree as their continuing-generation peers, which suggests the degree of acculturation for the first-generation students. Yet, interdependent motives were more salient with first-generation students than with the continuing-generation students. This could suggest that first-generation students may be more conflicted than their continuing-generation peers when a given situation causes opposing values to confront, such as prioritizing familial responsibilities versus individual responsibilities. Further analyses of the survey and other measures, such as the VAI, will help better understand these connections.

Many of the FIG mentors commented how much they enjoyed incorporating the DEI panel to represent a more diverse group of students. Though many of the same themes reoccurred from one panel to another, such as seeking tutoring services and getting involved on campus, each group of panelists was dynamic and unique.

The panelists were interviewed to get their perceptions about the DEI panel(s) and suggestions for future panels. Interesting subjects emerged from the interviews that offered some insight about the overall expression students may have regarding the panels, given that the audience members were not asked directly about the panel they attended. In terms of group composition, first-generation panelists were a smaller and more homogenous group that easily identified with 
their generational status, while continuing-generation panelists were not as likely to identify with their generational status ${ }^{23}$. At the end of the semester, panelists were asked for suggestions to improve the DEI panel activity. Many continuing-generation students thought that the panel failed to deliver a unified message to the audience and thought that the discussion of background was not as important as emphasized by the questions. In contrast, first-generation panelists suggested smaller changes to the panels, such as having a student facilitator, but did not have any suggestions about the content of the questions. Many first-generation panelists found it refreshing to incorporate social background and its relation to an individual's college experience. Despite these differences, both continuing- and first-generation panelists thought that the panels offered them a personal opportunity to get to know their fellow classmates in a way they had not considered in the past. The panel(s) also caused panelists to reflect on their own college experience in a way that had not been anticipated.

\section{Limitations}

A limitation to this study is the variability in the implementation of the interventions, particularly in the timing. As previously stated, the VAI was developed to take place immediately preceding a challenging academic task, thus mitigating the achievement gap. While this was attempted in our study, scheduling constraints required an alteration to schedule the VAI as early in the semester as possible in an effort to expose participants to the intervention before their first major exam. However, some of the FIG sections did the VAI intervention after their first major exam. The varying durations between the interventions and the survey could have a significant impact on how much participants benefitted from the module in the semester studied. Ongoing data collection (GPA, retention) will continue on this cohort in future semesters to determine if more changes are observed later.

Another factor that could not be controlled throughout this study is the student's attendance to the FIG classes each week. While absent students were encouraged to take part in the VAI writing exercise, many of them opted not to. For the students that were absent for the DEI panel, there was no second opportunity available to participate. Therefore, it was difficult to ensure that all participants would get the same experiences out of this module.

The interventions selected for this module were chosen in part because prior work suggested that they might have some positive benefits for continuing-generation students in terms of psychosocial adjustment to college, even if academic benefits may only arise for first-generation students. Hence, another area for future work is to analyze the survey data further with regard to presence of the sense of belonging and engagement with the university community.

Bibliography

1. Engle, J., \& Tinto, V. (2008). Moving Beyond Access: College Success for Low-Income, First-Generation Students. Pell Institute for the Study of Opportunity in Higher Education. 
2. Harackiewicz, J. M., Canning, E. A., Tibbets, Y., Giffen, C. J., Blair, S. S., Rouse, D. I., \& Janet, H. S. "Closing the Social Class Achievement Gap for First-Generation Students in Undergraduate Biology". Journal of Educational Psychology, 106(2), 375-389, (2013).

3. Horn, L., and Nunez, A.M. (2000). Mapping the Road to College: First-Generation Students' Math Track, Planning Strategies, and Context of Support (NCES 2000-153). U.S. Department of Education, National Center for Education Statistics. Washington, DC: U.S. Government Printing Office.

4. Choy, S.P. (2000). Low-Income Students: Who They Are and How They Pay for Their Education (NCES 2000-169). U.S. Department of Education, National Center for Education Statistics. Washington, DC: U.S. Government Printing Office.

5. Engle,J., Bermeo, A., \& O'Brien, C. (2006). Straight from the Source: What Works for First-Generation College Students. The Pell Institute for the Study of Opportunity in Higher Education.

6. Chen, X. (2005). First Generation Students in Postsecondary Education: A Look at Their College Transcripts (NCES 2005-171).U.S. Department of Education, National Center for Education Statistics. Washington, DC: U.S. Government Printing Office.

7. Ozga, J., \& Sukhnandan, L. "Undergraduate Non-Completion: Developing an Explanatory Model”. Higher Education Quarterly, 52(3), 316-333 (1998)..

8. Retention Project: 32. ASEE, 27 Aug. 2012. Web. 14 Mar. 2015. 〈http://www.asee.org/retention-project>.

9. Martin, J.P., Miller, M.K., \& Simmons, D.R., "Exploring The Theoretical Social Capital "Deficit" Of First Generation College Students: Implications For Engineering Education". International Journal of Engineering Education 30(4), 822-836, (2014).

10. Martin, J.P., Simmons, D.R., \& Yu S.L., "The role of social capital in the experiences of Hispanic women in engineering majors", Journal of Engineering Education, 102 (2), 2013, pp.227-243.

11. London, H. "Breaking Away: A Study of First-Generation College Students and Their Families." American Journal of Education, 97(2), 144-170, (1989).

12. Stephens, N.M., Fryberg, S.A., Markus, H.R., Johnson, C., Covarrubias, R. "Unseen disadvantage: How American universities' focus on independence undermines the academic performance of first-generation college students." Journal of Personality of Social Psychology, 102, 1178-1197, (2012).

13. Nunez, A.M., and Cuccaro-Alamin, S. (1998) First-Generation Students: Undergraduates Whose Parents Never Enrolled in Postsecondary Education (NCES 98-082). U.S. Department of Education. National Center for Education Statistics. Washington, DC: U.S. Government Printing Office.

14. Bowen, W.G., Kurzweil, M.A., \& Tobin, E.M. (2005). Equity and excellence in American higher education. Charlottesville: University of Virginia Press.

15. Bureau of Labor Statistics, U.S. Department of Labor, Occupational Outlook Handbook, 2014-15 Edition, Acknowledgments, on the Internet at http://www.bls.gov/ooh/about/acknowledgements.htm.

16. Burtner, J. "The use of discriminant analysis to investigate the influence of non-cognitive factors on engineering school persistence.” Journal of Engineering Education, 94, 335-338, (2005).

17. Seymour, E. \& Hewitt, N.M. (1997). Talking about leaving, why undergraduates leave the sciences. Westview Press, Boulder, CO. 
18. Moller-Wong, C. \& Eide, A. “An Engineering Student Retention Study.” Journal of Engineering Education, 86, 7-15, (1997).

19. Steele, C. Reducing Identity and Stereotype Threat: A New Hope. Whistling Vivaldi: And Other Clues to How Stereotypes Affect Us. 1st editon. New York: W.W. Norton, 2010. Xii-242. Print. Issues of Our Time (W.W. Norton \& Company).

20. Cohen, G.L., Garcia, J, Apfel N, \& Master A. "Reducing the Racial Achievement Gap: A SocialPsychological Intervention." Science, 313, 1307-310 (2006).

21. Cohen, G.L. \& Sherman, D.K. "The Psychology of Change: Self-Affirmation and Social Psychological Intervention.” Annual Review of Psychology, 65, 333-371 (2014).

22. Stephens, N.M., \& Destin, H.M. "Closing the Social-Class Achievement Gap: A Difference-Education Intervention Improves First-Generation Students' Academic Performance and All Students' College Transition.” Psychological Science, 25 (4), 943-953, (2014).

23. Paz, J., Cousins, M., Wilson, C., Blanchard, A., Sitabkhan, A., Mendez, C., Gonzalez, E., Pecen, F., Singh, G., Pineda, J., Chen, K., Wey, M., Major, M., Soberon, N., Momin, N., Chao, S., Mejia, W., \& Markey, M.K. "Telling our stories: benefits to student panelists." American Society for Engineering Education Gulf Southwestern Regional Conference, (to appear, 2015).

24. Stephens, N.M., Fryberg, S.A., Markus, H.R., \& Johnson, C.S. "Unseen Disadvantage: How American Universities' Focus On Independence Undermines The Academic Performance Of First-Generation College Students." Journal of Personality and Social Psychology, 102(6), 1178-1197, (2012).

25. DeAngelo, L., Franke, R., Hurtado, S., Pryor, J. H., \& Tran, S. Completing college: Assessing graduation rates at four-year institutions. Los Angeles: Higher Education Research Institute, UCLA (2011). 